\title{
Caminhos de mudanças sintático-semânticas no português arcaico
}

\section{ROSA VIRGÍNIA MATTOS E SILVA Universidade Federal da Bahia}

\section{Abstract}

In this paper I discuss some research results on syntactic variation and change which took place in Old Portuguese. Based on texts from the 14th and 15th centuries I discuss: (a) the variation involving ser/estar and the diffusion of estar to atributive structures (both locative and descriptive); (b) the variation between singular and plural as well as the loss of agreement marks in the Past Participle in those structures where in conjunction with haver or ter it could be reinterpreted as a compound tense; and (c) finally, I present evidence to show that in some syntactic and semantic contexts number agreement involving a verb and its subject was a variable phenomenon in Old Portuguese. 


\section{PRELIMINARES}

difusão lexical da mudança fônica voltou a primeiro plano na Lingüística
Histórica com o artigo de W. Wang de 1969 que, mais uma vez (lembro-
me das reações dos dialetólogos do século XIX), balançou a teoria
neogramática sobre o caráter "lexicalmente abrupto" embora "fonetica-
mente gradual" das mudanças fônicas. Os que têm acompanhado as discussões teóricas sobre o tema conhecem a revisão feita por Labov (1981), em que passa a admitir mudanças do tipo neogramático e do tipo difusionista, resumidas por ele próprio no seu texto-resenha de 1982 (p. 65). Conhecem também a posição definida como radical de Oliveira (1991: 103), para quem não há mudanças fônicas do tipo neogramático, embora possa haver resultado desse tipo em mudanças de longo alcance.

Labov tem então razão quando afirma, referindo-se aos trabalhos difusionistas chineses, liderados por Wang, que "a aceitação tradicional calma da regularidade da mudança fônica pode ser mantida apenas se se ignorar esses lingüistas e seus resultados" (1981:269).

A polêmica já está posta na mesa, portanto, há mais de dez anos. Centrou-se, como era de se prever - já que são o ponto ainda mais forte da Lingüística Histórica - nas mudanças fônicas.

Mollica (1989:268), na sua tese sobre variação sintática, no momento em que aborda o problema do queísmo/dequeísmo sob a luz difusionista, deixa isso, com propriedade, bem claro, ao afirmar que "os estudos difusionistas trabalham com fenômenos fonológicos predominantemente", talvez porque outros tipos de mudança fossem assumidos como difusionistas (cf., por exemplo, a afirmação de Wang (1969:14), para quem mudanças não-fônicas (lexicais, morfológicas, sintáticas) não são "obviamente" (é dele o qualificador) do tipo "lexicalmente abruptas").

Já em meados de 70, Naro e Lemle (1977:262) propõem, mencionando a motivação difusionista provocada pelo trabalho dos lingüistas chineses, um modelo para o processo de difusão de mudanças sintáticas, a partir da análise de aspectos da perda da marca de concordância no português, em que "o princípio da saliência" está na base do processo da implementação da mudança: a concordância é menos provável precisamente naquelas formas em que sua ausência seria menos saliente.

Entretanto, a questão da mudança difusionista versus abrupta também divide os estudiosos da mudança sintática. Basta lembrar, por exemplo, que os seguidores da deriva sapiriana e os sociolingüistas quantitativistas, estes, tanto ao tratar das mudanças em curso como das de longa duração, defendem a implementação difusionista da mudança. Destaque-se que o transition problem é um dos pontos fortes da teoria 
laboviana. Por sua vez as reestruturações abruptas para eliminar opacidades sintáticas fundamentam teorias formais da mudança. Mesmo que seus seguidores admitam os dados históricos que indicam a implementação gradual, essas são interpretadas como mudanças discretas nas estruturas gramaticais subjacentes. Lembro-me aqui, por exemplo, do trabalho de Lightfoot (1979).

No todo da questão, o que transparece unicamente como fato óbvio (recupero o qualificador de Wang), a meu ver, é que as teorias para a mudança refletem, diretamente, as teorias lingüísticas que formam e informam seus autores e não haveria de querer-se outra coisa, em nome da coerência científica. Se um dia confluírem as teorias, um novo período de calma (recuperando o qualificador de Labov) poderá vir a existir nas hostes da Lingüistica e, conseqüentemente, da Lingüística Histórica, se, nesse tempo, essa última ainda precisar de ser adjetivada.

Neste trabalho reúno dados de que disponho sobre pontos em variação e mudanças em curso no período arcaico do português (séc. XIII-XV), como contribuição à história da língua portuguesa, pouco pensada e estudada nas últimas décadas. Adianto, entretanto, que os pontos observados mostram que as variações e mudanças, nelas, caminham por estruturas determináveis no percurso cronológico observado.

Os fatos de que tratarei não são estritamente sintáticos; se quiser ser estruturalmente rigorosa e estilisticamente rebarbativa direi que são morfossintático-léxico-semânticos. Informarei sobre:

1. a variação de ser e estar e o avanço deste em estruturas atributivas;

2. a variação de haver $\mathrm{e}$ ter $\mathrm{e} o$ avanço deste em estruturas possessivas;

3. a variação singular/plural e a perda da marca de concordância no participio passado em estruturas com haver/ter analisáveis como tempo composto;

4. A variação singular/plural na forma verbal e sua relação de concordância com o sujeito do verbo. ${ }^{1}$

O meu ponto de partida é uma análise extensiva que realizei sobre documento da $2^{\mathrm{a}}$. metade do século XIV. Daí verifico os fatos em documentação da $1^{\mathrm{a}}$ e $2^{\mathrm{a}}$ metades do século XV. A dimensão cronológica das questões tratadas abrange o português literário, em prosa, trecentista e quatrocentista.

Vale chamar atenção para o fato de que os estudos lingüísticos empiricos sobre o português arcaico dispõem de documentação de três tipos: documentos jurídicos ou notariais, documentos literários poéticos, documentos literários em prosa. Não se dispõe para o período arcaico de documentação qualificada hoje de menos formal como sejam: textos de natureza dramática, cartas particulares, documentação esta que começa a aparecer no século XVI, por razões históricas conhecidas. Assim sendo, considero que, para os estudos sintático-semânticos, é a documentação literária em prosa a mais rica para uma aproximação histórica, estando-se, contudo, sempre consciente de que se está trabalhando sobre textos escritos, na maior parte dos casos traduzidos de outras línguas (latim, castelhano, francês...), e que as informações daí depreendidas são apenas pistas ou rastros para o que seria o português falado de então. 
Vale ainda chamar atenção para um aspecto da questão cronológica: os manuscritos medievais portugueses disponiveis, quer de poesias quer da prosa literária, não são originais e sim cópias mais ou menos contemporâneas a sua data de origem. Este fato exige que a história interna de cada texto seja conhecida, para que não se tirem conclusões apressadas sobre a datação dos fenômenos lingüísticos pesquisados.

Outro fato significativo e que hoje precisa ser recordado é o de que, para a seleção de qualquer corpus que represente o português na sua fase arcaica, se faz necessário avaliar previamente a edição com que se trabalhará porque há, na tradição filológica, edições que podem ser úteis a historiadores e estudiosos da literatura, mas que podem estar prejudicadas para estudos de língua, já que seus editores interferem, mais ou menos, sem esclarecer, nos dados lingüísticos dos manuscritos que editam.

A seleção da documentação quatrocentista aqui analisada foi condicionada pelas edições acessiveis e de credibilidade e também pela dimensão dos textos. ${ }^{2}$

\section{SER E ESTAR EM ESTRUTURAS ATRIBUTIVAS}

O português opõe semanticamente os verbos ser/estar. Daí a procedência de considerá-los não como verbos-cópula, mas verbos predicadores; assim os analisam Mateus et alii (1983:138):

a oposição ser/estar é uma das formas de que o português dispõe para exprimir a distinção entre predicadores de propriedades de individuais e predicadores de propriedades de manifestações temporalmente limitadas de individuais.

Essa distinção semântica que, daqui por diante, designarei, por mais simples, de permanente versus transitório não estava estabelecida no período arcaico do português.

Um leitor de hoje, e pouco rigoroso, de textos arcaicos poderá supor que o verbo ser cobria o campo de estar nas estruturas atributivas; outro, mais rigoroso, poderá supor que os dois verbos variavam (e não estaria errado) nessas estruturas, mas ambos perceberiam que a oposição acima descrita não existia.

As frases de (1) a (8) mostram isso:

(A) 1. Dementre no mundo era DSG 2.1.4

2. Cousas que derredor estavam DSG 3.1.9

3. Seendo o honrado padre en sa cela DSG 2.7.2

4. O servo de Deus estando en sa cela DSG 2.11.3

(B) 5. As sas duas irmããs que eran mui coitadas pola sa morte, veeron ao bispo DSG 1.29.7

6. Estando hũ dia seu padre $\mathrm{e}$ os físicos mui coitados com eles, disse-lhis o bispo... DSG 4.10.56 
7. Ca as donas que enton presentes foron, contaran-no aas outras DSG 4.11.27

8. Fez sa oraçon estando el-rei presente DSG 3.37.6

No grupo (A) ((1) - (4)) estão estruturas que denomino de atributivas locativas e no grupo (B) ((5) - (8)) estão as que denomino de atributivas descritivas.

Observando-se esses exemplos, pode-se marcar o atributo quer locativo quer descritivo com o traço semântico |+ transitório | e é neles que a variação ser/estar ocorria, já que nos atributos marcados como |+ permanente | é o verbo ser o predicador. Excluí desta exposição outros verbos cotrelatos que ocorriam nessas distribuições, tais como: andar, jazer, ficar, tornar, mãer, permanecer ( cf. Mattos e Silva, 1987a e 1989).

A análise das ocorrências de ser, estar $^{3}$ e verbos correlatos, considerando-se, inclusive, subgrupos semânticos nos atributos transitórios e permanentes, em extenso documento da $2^{\mathrm{a}}$ metade do século XIV (DSG), informou, em síntese, que:

. ser predomina nas locativas em geral, com pequena diferença sobre estar: $52.8 \%: 47.2 \%$;

. estar já predomina sobre ser nas locativas transitórias: 70.7\% : 29.3\%;

. ser, marcantemente, predominava nas descritivas, tanto permanentes como transitórias, em relação a estar: $92.2 \%: 7.8 \%$.

Esses dados permitiram levantar a hipótese de que a marca | + transitório|, expressa por estar, se firmou primeiro nas atributivas locativas que nas descritivas.

A observação em corpus da $1^{\mathrm{a}}$ metade do século XV (CDP) apresentou os seguintes resultados (Sepúlveda Neto, 1989):

$\begin{array}{cccc} & \text { SER } & \text { ESTAR } \\ \text { LOC. } 1+\text { transitório } & 26.2 \% & 73.8 \% \\ \text { DESC. } 1+\text { transitório } & 77.8 \% & 22.2 \%\end{array}$

Os dados indicaram que a mudança que resultou na oposição semântica entre ser e estar em estruturas atributivas ainda estava em curso: estar, expressão de atributos transitórios, continuou a crescer nos locativos e avançou nos descritivos. Observado um pequeno corpus de 1540 (DVV), a autora verificou que, um século depois, nos locativos não mais ocorre ser e que, nos descritivos, só ocorreu ser uma vez, em tradução de texto latino citado que tem como predicador o verbo esse (Ibid.: 85).

Esses dados dos séculos XIV, XV e XVI são indicadores de que a mudança que levou à oposição semântica ser/estar em estruturas atributivas estava concluída no século XVI e se difundiu dos contextos locativos para os descritivos. 
Vale recordar que na sua história pregressa estar tem como étimo stare, 'estar de pé' - e nessa acepção está documentado no português pelo menos até fins do século XIV - enquanto ser tem uma história complexa de convergência dos verbos latinos sedere, 'estar sentado' - estando ainda em uso, nessa acepção, pelo menos até fins do século XIV - e esse, 'ser'. Esse fato permite sugerir que o traço|+ transitório| é próprio, desde a sua origem, a estar, enquanto em ser confluem o | + transitório / de sedere e o |+ permanente $\mid$ de esse. Não é sem razão histórica, portanto, que, definida a oposição no português, foi estar o verbo escolhido para expressar a transitoriedade, ou seja, a propriedade de individual temporalmente limitada. Em termos labovianos, talvez se pudesse dizer, transferindo da fonologia para a semântica, que é esta uma mudança encaixada na estrutura, vista essa numa dimensão histórica secular.

\section{HAVER E TER EM ESTRUTURAS POSSESSIVAS}

O leitor atual de textos do português arcaico percebe que tanto ter como haver eram utilizados com o traço semântico de posse. Ocupavam, portanto, a posição de predicado em estruturas sintáticas semanticamente possessivas; variação que não existe no português atual, já que haver, hoje, não ocupa mais essa posição por não portar mais o traço semântico referido.

A análise das ocorrências de estruturas com haver/ter em corpus da $2^{\mathrm{a}}$ metade do século XIV (DSG) permitiu-me precisar o uso de haver e ter naquela sincronia. Um dado primeiro, significativo, foi a alta frequiência de haver sobre ter (803 vs 119 ocorrências) (Mattos e Silva, 1989:587-95)

Quanto às estruturas de posse, atestei que a variação na seleção de haver ou ter estava condicionada à natureza semântica do complemento do verbo, o objeto possuído. Defini então três tipos semânticos para o complemento:

.qualidades inerentes, não transferíveis, tais como características ou estados físicos do possuidor, sujeito da frase (abrev. QI);

- qualidades adquiríveis imateriais: morais, espirituais, intelectuais, afetivas, sociais (abrev. AI);

. objetos materiais adquiriveis, externos ao possuidor (abrev. AM).

Os dados encontrados para o séc. XIV, a partir dos tipos descritos, se resumem em:

. no tipo QI, só ocorria haver (haver barvas, ceguidade, cinquenta anos...);

. nos tipos AI e AM, haver e ter parecem variar, com predominância de haver para $\mathrm{AI}$ e de ter para AM:

$\begin{array}{ccc} & \text { HAVER } & \text { TER } \\ \text { AI } & 80 \% & 18 \% \\ \text { AM } & 20 \% & 82 \%\end{array}$


Examinando-se item a item do léxico que compõe esses complementos, verificouse, com surpresa, que ter, na estrutura AI, só ocorre com o complemento fe (ter fe, a par de aver fe) enquanto haver vem seguido de mais de 20 itens como, por exemplo, fe, graça, poder, poderio, ira... Esse dado indicou que a variação haver/ter, neste momento, ocorria, de fato, nas estruturas do tipo AM, em frases como as de (9) a (14):

(09) Pode logo aver aprestidados logares 2.3.55

(10) todos aqueles logares tẽe os lombardos 3.12.18

(11) Ele non pode aver remedio 1.5 .53

(12) Ele tiinha sas meezîhas 4.46.8.

(13) Ovelhas que el avia 3.16 .3

(14) Acharon hũũ homen terr hũũ carneiro 3.23.11

Observados os mesmos fatos em corpora do séc. XV, verificou-se, cronologicamente:

a. em texto situável entre 1410-1420, cópia do ms. trecentista (LRR):

- QI: sempre haver (aspeito, sembrante);

- AI: sempre haver (cuidado, nome, força, siso...), com a exceção de ter filho que varia com haver filho;

- AM: variam haver e ter (haver guarda, ter castelo...).

Situação, portanto, análoga ao DSG trecentista, confirmando que só no contexto do tipo AM haver/ter variam e, excepcionalmente, em AI.

b. em texto escrito entre 1418-1442, mas ms. dos fins do XV (CDP):

Haver e ter variam nos três tipos observados, inclusive QI, mas em todos predomina haver sobre ter (p. ex.: QI: haver vista, teer voz; AI: haver paz, ter bem; AM: haver guerra, ter serviço).

c. em texto de $1468-1477$ (IC):

A situação aí documentada confirma a anterior; acrescenta que ter já predomina sobre haver nas três estruturas (p. ex.: QI: ter oolhos; AI: haver paz, ter paz; AM: haver nẽhũa cousa, ter cousas).

Desses dados se pode inferir que haver/ter em estruturas possessivas variavam, como descrito, no português arcaico, predominando primeiro haver, mas, já na $2^{\mathrm{a}}$ metade do séc. XV, ter; e que a difusão de ter, que excluirá haver dessas estruturas, parte dos contextos do tipo AM para os de tipo AI e, por fim, atinge os de tipo QI, estruturas essas em que, semanticamente, pode-se interpretar, haver é antes predicador de atributo que um "transitivo" com o traço semântico de posse. 
A história semântica pregressa dessas formas sugere o curso dessa mudança. No latim, o verbo básico para a expressão da posse é habere e, segundo Gaffiot (1934, s.v. habere), a sua acepção primeira é 'ter em sua posse', 'guardar' e, subseqüentemente, entre os usos figurados, 'ter na mão'; enquanto ter (Gaffiot, 1934, s.v.tenere) tem como acep̧̧ão básica 'ter algo na mão', 'obter', sendo que outras acepções secundárias são 'manter', 'reter' etc. Já havia no latim, portanto, a interseção semântica entre habere/tenere na expressão de algo concreto, 'ter na mão'. Na história documentada do português, os seus continuadores já aparecem em variação nesse sentido, desde momento recuado, como vimos; daí - do contexto AM - ter-se difundido para os outros, enquanto haver vai se especializar como verbo existencial, à medida que ser deixa de ser o verbo para a expressão desse conteúdo. $O$ processo de mudança de haver 'de posse' para 'existencial' já está documentado no chamado 'latim vulgar', segundo Grandgent (1952:27-8), nos séculos IV e V, concorrendo já então com esse.

Mas isso já é outra história, embora com esta intertelacionada, do mesmo modo que dessa história participa a expansão atual de ter para o 'existencial', perdendo haver também nessa acepção e estrutura para ter. Essas últimas referências são um chamado para fato de que, na história do português, haver, ter, ser, estar estão interligados nas estruturas possessivas, atributivas e existenciais.

Voltando para o haver/ter, cuja difusão esbocei, pode-se dizer que essa mudança que se processava no periodo arcaico já vinha prefigurada ou 'encaixada' na estrutura latina e se definiu pelos caminhos traçados desde as origens históricas do português.

\section{HAVER E TER EM ESTRUTURAS DE TEMPO COMPOSTO}

Neste ponto levarei em conta não só os dados dos meus trabalhos $(1981,1989)$ mas também o de Naro e Lemle (1977). Não tratarei aqui da comutação haver/ter em estruturas com particípio passado, como no anterior, nas de posse. Vale, entretanto, dizer que os dois vetbos variam neste contexto no periodo arcaico (Mattos e Silva, 1981:98), sem que se possa afirmar que já então ter predomina sobre haver, mas sim que as ocorrências de ter cresciam em relação às de haver, do séc. XV para o XVI (Naro e Lemle, 1977:267).

O problema aqui em foco é: no período arcaico, estruturas como as exemplificadas de (15) a (20) indicam que o particípio passado (PP) é adjetivador do complemento direto (CD) de haver/ter:

(15) todos bẽes mh' á feitos DSG 4.32 .8

(16) aquelas cousas que ten aparelhadas DSG. 2.16.26

(17) e despois que toda sua companha ouve concertada LRR XI, 74-75.

(18) e, tanto que ele teve quisado | todo |, foi-se espedir del rei LRR V. 106-107

(19) e non soomente d'os | serviços | que faziam a ele, mas os que aviam feitos a seu padre CDP 1.50

(20) e non ousarom d'entrar na camera por a defesa que el-rrei tiinha posta CDP 7.50 
Nesses exemplos da $2^{\underline{a}}$ metade do século XIV (DSG) e da $1^{\underline{a}}$ metade do século XV (LRR e CDP), haver/ter são "verbos principais" de posse e não são analisáveis como "auxiliares", e o adjetivo-PP é constituinte do SN complemento direto; o PP, portanto, não é constituinte do SV. Nesse mesmo conjunto de textos, na LRR, aparecem as ocortências (21) e (22), que são interpretáveis como haver/ter + PP, "tempo composto":

(21) E a molher do conde, que já havia sabido | e não sabida | de sua filha toda sua fazenda LRR VIII. 15-16.

(22) E non sabedes vós quanto afam e trabalho ayades tomado | não tomados | e quantas espadadas e seetadas havedes levadas LRR X. 13-14

Exemplos do mesmo tipo Naro e Lemle encontraram na Crônica de d. João I, de Fernão Lopes, do mesmo autor, portanto, da CDP dos exemplos (19) e (20). Considerem-se os exemplos (23) e (24):

(23) a que todo o reino tinha feito menagem de o receber por senhor CDJ I. 209

(24) a menagem que por o lugar tinha feita CDJ I. 173

Esses exemplos de variação na concordância do $P P$ com o $C D$ são evidências de que já então conviviam as duas estruturas: a inovadora, em que ter/haver são reanalisados como verbos auxiliares, constituindo com o PP o SV, e a antiga, de origem latina, em que haver/ter são verbos principais transitivos e o PP é Adj. e não V, estrutura que ocorre até hoje também:

(25) Eu tinha as cartas escritas quando ele chegou.

(26) Eu tinha escrito as cartas quando ele chegou.

Esta reanálise estrutural complexa já teria ocorrido, senão antes, pelo menos na $1^{\mathrm{a}}$ metade do século XV. Naro e Lemle (1977:265) afirmam que já é do século XIV, a partir de dados do Orto do Esposo, datado de 1385. Entretanto, a documentação trecentista que descrevi (DSG) não apresenta nenhuma estrutura desse tipo. Contudo, esse texto deve ser mais recuado naquele século. Meus dados, portanto, não desmentem Naro e Lemle.

Como se teria de difundido essa mudança?

É preciso reter que na estrutura mais antiga o $C D$ não tem posição fixa, podendo preceder, suceder ou estar entre haver/ter e o elemento participial, ou ainda ser $ø$. Por sua vez, ter/haver podem também preceder ou suceder o PP. No corpus trecentista e quatrocentista que analisei (1981:101), ocorrem as distribuições abaixo, com suas respectivas frequências: 


\begin{tabular}{c|c|c}
\hline Tipo & Distribuição & Freqüencia \\
\hline 1 & $\mathrm{t} / \mathrm{h}+\mathrm{PP}+\mathrm{CD}$ & 21 \\
2 & $\mathrm{t} / \mathrm{h}+\mathrm{CD}+\mathrm{PP}$ & 15 \\
3 & $\mathrm{CD}+\mathrm{t} / \mathrm{h}+\mathrm{PP}$ & 94 \\
4 & $\mathrm{PP}+\mathrm{t} / \mathrm{h}+\mathrm{CD}$ & 2 \\
5 & $\mathrm{CD}+\mathrm{PP}+\mathrm{t} / \mathrm{h}$ & 4 \\
6 & $\mathrm{t} / \mathrm{h}+\mathrm{PP}$ & 17 \\
\hline
\end{tabular}

Observe-se nesses dados que as distribuições mais freqüentes são a 3 , em que CD é um relativo, sem marca de gênero e número; a 1 , em que $C D$ sucede $t / h+P P ; e ~ a ~ 6$, em que o CD é ø. Naro e Lemle (1977:266) analisam e quantificam as distribuiçōes do tipo 1,2 e 3 do quadro acima. Considerando-se esses dados, a não-concordância do PP ocorre mais freqüentemente em 3 , seguida por $1 ; 2$ não é afetado pela mudança, já que essa estrutura se mantém até hoje (cf. exs. 25 e 26).

Os dados permitem supor que, no que se refere à difusão da mudança nas estruturas sintagmáticas, a perda da concordância do $\mathrm{PP} e$, conseqüentemente, sua análise como PP-verbal e não como ADJ, partiu dos contextos em que a concordância não é saliente, sendo considerados mais salientes aqueles contextos em que $C D$, sintagma nominal, precede $t / h$ e PP (Naro e Lemle, 1977:266).

Conjugando os meus dados e reflexões com os de Naro e Lemle pode-se propor que a difusão da mudança foi favorecida pela estrutura na distribuição sintagmática, já existente na língua, em que $P P$ fica sem marca de concordância, já que $C D$ pode ser masculino e singular, bem como pela estrutura em que $C D$ é vazio, recuperável como pronome neutro do tipo isto, tudo. Esse contexto se mostrou freqüente nos meus dados (tipo 6), em exemplos como:

(27) seu neto mandara pedir ajuda segundo antes avemos contado CDP 19.1415

(28) morto el-rei como avees ouvido, reinou seu filho CDP 1.3

(29) tanto que el teve guisado, foi-se espedir LRR V. 106-107.

Nos contextos em que PP pode ser flexionado por concordância com o $C D$ pode-se supor que a difusão percorria o seguinte curso no séc. XV:

a. Contextos em que $\mathrm{CD}$ está preenchido pelo relativo, não marcado em gênero e número: nos dados de Naro e Lemle há $31.6 \%$ de casos nessa distribuição sem marca de concordância no séc. XV, mas ø no XIV. Os meus resultados reforçam a significação desse contexto, que é o mais freqüente;

b. contextos em que CD sucede haver/ter, distribuição própria ao tempo composto: os dados de Naro e Lemle indicam, para o século XV, 17.7\% de casos em que a perda da concordância está documentada e ø para o XIV. Nos meus dados essa estrutura é a segunda em frequiência(cf. quadro precedente). 
Os dados também informam sobre a difusão a depender da classe do verbo. Os dados que analisei, séc. XIV e XV, identificaram 63 itens verbais-PP, todos transitivos. Naro e Lemle quantificam a difusão de transitivo para intransitivo, do séc. XIV para o XVI: $2 \%$ de intransitivo no séc. XIV para $10 \%$ no séc. XV e $17 \%$ no XVI (p. 267, Q10).

Possivelmente outros fatores, tanto lingüísticos como sociolingüisticos (já Naro e Lemle observam a difusão dos transitivos para intransitivo em textos que consideram menos ou mais formais), entraram nessa história complexa. Ficam aqui essas pistas para futuras escavações.

\section{A VARIAÇÃO NA CONCORDÂNCIA VERBO-NOMINAL}

Neste tópico quero apenas chamar a atenção para o fato de que a concordância verbo-nominal, embora seguisse a regra geral sujeito singular/verbo singular, sujeito plural/verbo plural, apresentava-se já facultativa em alguns contextos. Observei isso no corpus trecentista dos DSG (1989:488-507; e 1986). Este problema, é claro, deverá ser estudado em outros corpora do período arcaico. Este caso está relacionado ao tópico anterior e indica que não era a concordância facultativa apenas entre PP e CD. Nato e Lemle, ao discutirem o tópico anterior, dizem que esta variação na concordância PP/CD é uma peculiaridade aparentemente não partilhada com as regras de concordância naquele período (1977:226).

Os dados trecentistas mostram haver variação na concordância verbo-nominal por interferência, pelo menos, do fator distância entre sujeito e verbo, posposição do sujeito, tipo de sujeito e de fator semântico, como uma interpretação singular ou plural para o sujeito. Considerarei, aqui, sumariamente, estruturas com sujeito simples, como em (30) e (31), com sujeito composto, como nos exemplos de (32) a (38), e com sujeito expresso por substantivo coletivo, como nos exemplos de (39) a (48).

a. Sujeito simples

(30) A maldade dos que ficam no mundo mereceron que aqueles que poderiam profeitar aos outros saian-se do mundo. 3.37.98

(31) Ca a homildade grande do homen bõõ, que queria que os seus bõõs feitos sejam ascondudos, esto deven a querer... 1.17.31

Nessas duas ocorrências a concordância regular não se faz pela interferência do complemento plural do sujeito em (30) enquanto que em (31) deven, distante de homen bõõ, leva a marca do plural talvez não só por isso, mas por ser interpretado com o sentido genérico plural.

b. Sujeito composto:

(32) E aos braados veo o bispo e todos aqueles... 1.19 .8

Neste caso o sujeito é composto e posposto; o verbo está no singular. J. Huber (1933: § 446) já chama a atenção para esse tipo de concordância com sujeito posposto 
composto. No corpus que analisei, a posposição do sujeito simples não interfere na regra geral.

Quando o sujeito é composto de nominais parassinônimos, a concordância é variável tanto quando o sujeito é anteposto, como em (33) e (34), como quando é posposto, como em (35) e (36):

(33) O sabor do luxurioso e o prazer he vermen e fedor 4.34 .18

(34) A mancebia e o deleito son cousas vããs 4.4.21

(35) Ei razon de me creceren lagrimas e door e choro e amargura 1.1.22

(36) E pelas moradas dalgũus a que tangia a nevoa e o fedor 4.34 .15

Também varia a concordância se o sujeito composto parassinônimo está representado pelo relativo que introduz a sentença encaixada, como em (37) e (38):

(37) A nevoa e o fedor que do rio recudia 4.34.15

(38) E pelas moradas daqueles outros a que non podia atanger a nevoa e do fedor que do rio recudian DSG 4.34.19

Os exemplos utilizados, intencionalmente, mostram que a variação ocorre não apenas quando a marca de plural do verbo é o traço nasal, representado no ms. ou por til ou por $\mathbf{m}, \mathbf{n}$.

c. Sujeito coletivo:

Huber (1933: § 447) afirma que, se o sujeito é coletivo, o verbo vai para o plural. Observei que, nesse caso, também variava a concordância e que algumas condições favoreciam a escolha da forma verbal:

- Se contíguo, anteposto ou posposto, o verbo está no singular:

(39) E todo o poboo se ajuntou pera veer 3.12.7

(40) Nem er ficou gente nem hũa 3.9.15

- a maior distância entre sujeito e verbo favorece a variação:

(41) Toda aquela companha dos spiritos maaos desapareceu 3.8.21

(42) Idolo a que o poboo sandeu de toda aquela terra fazian honra come a Deus 2.8.44

(43) e daquesta medês dá testemõio todo o poboo que enton era naquela cidade 3.12.13

(44) Hũa mui gram rua em que morava muita gente que primeiramente oraran os idolos 2.19 .2 
(45) Companha grande dos lombardos que veeron veer a morte do santo 3.37.65

(46) Gente dos lombardos que era mui cruevil usou de toda sua crueza 3.37.123

(47). E mandou que toda a outra gente que soia andar con el que fossen com el e levassen boas vestiduras 2.14 .7

(48) E a gente muita que estava na eigreja e querian fugir e non avian per u $e$ temian que durasse ali tanto aquela agua que morressen de fame e de sede e bevian daquela agua 3.20 .9

Em (41) e (42), entre o sujeito e o verbo está um sintagma complemento; em (43) e (44) o sujeito coletivo está representado pelo relativo sujeito, estando o verbo em sentença encaixada; em (45) e (46), entre o sujeito e o verbo, estão um sintagma complemento e o que relativo, referente ao sujeito coletivo; em (47) e (48), o verbo está no singular na relativa contígua ao sujeito coletivo e no plural nas mais distantes.

Tais dados são indícios de que já no período arcaico a posição e a distância do sujeito em relação ao verbo, além de fatores semânticos, são favorecedores à variação na concordância verbo-nominal. Tais informaçôes históricas podem contribuir para os estudos sincrônicos sobre variação/mudança nas regras de concordância do português contemporâneo.

Não considero mais que sondagens os estudos aqui apresentados. Eles exigem pesquisas mais extensivas e aprofundadas que comprovem ou não, mas enriqueçam e tornem mais preciso o conhecimento do português nos caminhos da sua história. ${ }^{4}$

\section{NOTAS}

${ }^{1}$ Os dados que discutirei estão já divulgados em artigos de minha autoria (1981, 1986, 1987a, 1987b) e nas Estruturas trecentistas (1989); também em dissertação de Mestrado orientada por mim (Sepúlveda Netto, 1989).

${ }^{2}$ Os textos-base dos estudos mencionados na Nota 1 e aqui são, em ordem cronológica:

$2^{2}$ metade do século XIV: A mais antiga versão portuguesa dos 'Quatro Livros dos Diálogos de São Gregório'. Edição crítica de R.V. Mattos e Silva. Tese de Doutoramento. São Paulo, USP, 1971. Mimeog. (Aceita para publicação em 1983 pelo IN-CM, Liboa). Abrev. DSG.

$1^{\text {a }}$ metade do século XV:

- A lenda do rei Rodrigo. Edição crítica de L.F Lindley Cintra. Lisboa, Ed. Verbo, 1964. Abrev, LRR 
- A crônica de d. Pedro, de Fernão Lopes. Edição crítica de G. Macchi. Roma, Ed. Atheneo, 1966. Abrev. CDP.

$2^{\mathbf{a}}$ metade do século $\mathrm{XV}$ :

- A linguagem da Imitação de Cristo. Edição crítica de I.V. Cepeda, Lisboa, CEF, 1962. Abrev. IC.

$1^{\mathrm{a}}$ metade do século XVI:

- Diálogo da Viciosa Vergonha, de João de Barros. Edição crítica de M.L. Buescu, in Gramática da língua portuguesa. Lisboa, Faculdade de Letras, 1971. Abrev. DVV.

${ }^{3}$ Como ilustração, nos DSG, para 1648 ocortências de ser, há 238 de estar, em todas as suas possibilidades estruturais.

${ }^{4}$ Tenho pronto um projeto, encaminhado ao CNPq, sobre Variação e mudança no português arcaico, cujo objetivo é retornar esses tópicos, além de outros, com base em corpus do séc. XIII ao XV e com pretensão de confrontá-lo com corpus do português contemporâneo.

\section{REFERÊNCIAS BIBLIOGRÁFICAS}

GAFFIOT, F. Dictionnaire illustré latin-français. Paris: Hachette, 1934.

GRANDGENT, C. H. Introducción al latin vulgar. Madrid, 1952.

HUBER, J. Altportugiesiches Elementarbuech. Heidelber, Carl Winters. Universitätsbuchhandlung, 1933.

LABOV, William. Resolving the neogrammarian controversy. Language, v. 57, n.2, p. 267-308, junho, 1981.

LABOV, William. Building on empirical foundations. In: LEHMANN, W., MALKIEL, Y. (eds.). Perspectives on historical linguistics. Amsterdam/Philadelphia, John Benjamins, 1982. p. 17-92.

LIGHTFOOT, David. Principles of diachronic syntax. Cambridge: Cambridge University Press, 1979.

MATHEUS, M.H. et alii. Gramática da língua portuguesa. Coimbra: Almedina, 1983.

MATTOS e SILVA, Rosa Virgínia. Um aspecto do auxíliar no português arcaico. Tulane studies in romance languages, Tulane, n. 10, p. 93-109, 1981.

- Contribuição para a leitura crítica de textos medievais portugueses: sintaxe e grafia. In: COLLOQUE DE CRITIQUE TEXTUELLE PORTUGAISE, 1986, Paris. Actes... Paris: Gulbenkian, 1986. p. 85-98. 
- - Ser, estar, jazer, andar no português trecentista. Arquivos do centro cultural português, 23, Lisboa/Paris: Gulbenkian, 1987. p. 31-47.

— Ter ou haver em estruturas de posse. Inédito, 17 p. (Mimeogr.).

— Estruturas trecentistas. Lisboa: Imprensa Nacional-Casa da Moeda, 1989.

MOLLICA, Maria Cecilia M. Queísmo e dequeísmo no português do Brasil. Tese de Doutoramento, Rio de Janeiro, UFRJ, 1989. 306 p. Tese (Doutorado), Universidade Federal do Rio de Janeiro - Faculdade de Letras, 1989.

NARO, Anthony J., LEMLE, Miriam. Syntactic diffusion. Ciência e Cultura, São Paulo, v. 29, n. 3, p. 259-68, 1977.

OLIVEIRA, Marco A. de. The neogrammarian controversy revisited. International journal of the sociology of language, Berlin, v. 89, p. 93-105, 1991.

SEPÚLVEDA NETTO, M.S. Ser, estar: um estudo de variação e mudança em curso no português antigo. Salvador, UFBa, 1989, Dissertação (Mestrado) Universidade Federal da Bahia - Instituto de Letras, 1989.

WANG, W. S-Y. Competing changes as a cause of residue. Language, v. 45, n.1, p.9-25, março, 1969. 